Polymer Journal, Vol. 38, No. 9, pp. 897-904 (2006)

(C) 2006 The Society of Polymer Science, Japan

\title{
Studies of Novel Copolymers for Deep-UV Photoresists. I. Synthesis and Properties of Poly(Styrene-co-Silicon-containing maleimide)
}

\author{
Wei-Jye $\mathrm{SHU}^{\dagger}$ \\ Department of Chemical and Material Engineering, Ta-Hwa Institute of Technology, \\ 1, Ta-Hwa Road, Chiung-Lin, Hsinchu 30743, Taiwan, ROC
}

(Received December 7, 2005; Accepted May 22, 2006; Published July 28, 2006)

\begin{abstract}
Soluble copolymers of trimethyl (4-( $N$-maleimido) phenoxy) silane (TMMS) with styrene-series monomers were synthesized by radical polymerization in toluene at $70^{\circ} \mathrm{C}$ using $2,2^{\prime}$-azobisisobutyronitrile (AIBN) as initiator. The comonomer reactivity ratios were calculated by the conventional Fineman-Ross and Kelen-Tüdos methods and a nonlinear least-squares Tidwell-Mortimer method. The glass transition temperatures $\left(T_{\mathrm{g}} \mathrm{s}\right)$ and thermal degradation of copolymers were determined by differential scanning calorimetric (DSC) and thermo-gravimetric analysis (TGA) methods, respectively. The comonomer reactivity ratio of TMMS with styrene was changed from a alternating to middle type between alternating and ideal copolymerization for the side-chain of TMMS and the deactivators of styrene. The curves of $T_{\mathrm{g}} \mathrm{s}$ versus the different compositions of the above synthesized styrene-maleimide copolymers matched the modified Johnston's equation as increasing the affect of weight ratio on alternating-segment, and exhibited an S-shaped curve of deviation in comparison with the Fox's equation. The maleimide-segments and styrene-segments within these copolymers were completely compatible and the thermal stability and flame retardancy of polystyrene could be enhanced simultaneously via the introduction of silicon-containing maleimide.

[doi:10.1295/polymj.PJ2005186]

KEY WORDS Poly(styrene-co-maleimide) / Copolymerization / Reactivity Ratio /
\end{abstract}

Maleimide polymers have good thermal stability with high glass transition temperature $\left(T_{\mathrm{g}}\right)$ due to their polar five membered imide ring structure. The functional polymaleimides made from various functionalized maleimide monomers also provide some desirable properties. $N$-aryl maleimide (AM) monomers, such as $N$-phenyl maleimide (PM), $N$-hydroxyphenyl maleimide (HPM) and halide-substituted $N$-hydroxyphenyl maleimide (XHPM), were usually copolymerized with ethylene or propylene series monomers to promote their heat and fire resistance. Many researches about the AM copolymers, such as the copolymers with styrene, ${ }^{1-4}$ methyl methacrylate, ${ }^{5-7}$ acrylonitrile $^{8}$ or vinyl acetate, ${ }^{9}$ have been reported.

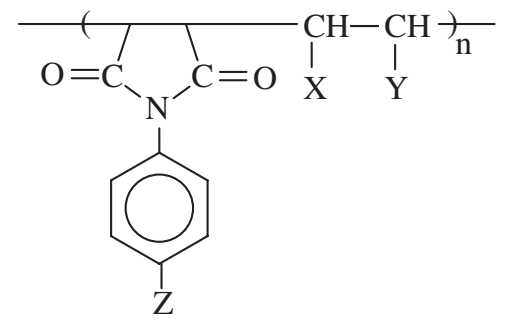

These copolymers synthesized by introducing the rigid and high thermal stability of AM segment own the higher softening points (or $T_{\mathrm{g}}$ ) and good fire resistance. Comparing the double bonds of AM and styrene comonomers with poor-electron and rich-electron density, respectively, a nearby complete alternating copolymer can be formed by free radical copolymerization. The copolymerization behavior of truly alternating styrene-maleic anhydride copolymer has already been reported by many researches. ${ }^{10-13}$ But, the silicon-containing AM systems are still rarely seen in literature.

Up to now, applications of $\mathrm{N}$-substituted maleimide polymers include photoresist with high $T_{\mathrm{g}},{ }^{14,15}$ flexibilizer for thermosetting polymers, ${ }^{16-18}$ non-linear polymer with high $T_{\mathrm{g}}$ and flame retardant ${ }^{19}$ etc. Some $\mathrm{N}$-protected polymaleimides have been investigated for their applicability as thermally-stable resist materials in the deep ultraviolet (DUV) region based on the chemical amplification concept. ${ }^{20-23}$ The photoresist film should possess high resolution, high sensitivity, high etching resistance, good thermal stability, and high adhesion for the lithographic processes. Incorporating silicon in the polymaleimide structure could advantageously provide good dry-etch resistance and enhanced adhesion to substrates. ${ }^{24,25}$

Our team has already designed a series of different silicon-containing side chains introducing into $\mathrm{N}$-aryl maleimides with high thermal stability, which could be polymerized by free radical initiator to form the soluble homopolymer. ${ }^{26}$ These silicon-containing maleimides will then be combined with styrene-series

${ }^{\dagger}$ To whom correspondence should be addressed (Tel: +886-3-5923551, Fax: +886-3-5927310, E-mail: shu@ thit.edu.tw). 
monomers in order to obtain various copolymers. They might be useful in the application of deep-UV photoresist for the acid-degradable side-chain within maleimides and styrenes. The copolymerization of a series of silicon-containing maleimide monomers with styrene have also been discussed simultaneously. In this paper we will discuss the reactivity ratios of four styrene-series monomers/silicon-containing $N$ aryl maleimide pairs in copolymerization to study their copolymerized behaviors. The $T_{\mathrm{g}} \mathrm{s}$ and thermal stabilities of the above synthesized copolymers are also discussed. The possibility of these copolymers applied as photoresist materials will then be confirmed further more.

\section{EXPERIMENTAL}

\section{Materials}

Styrene (St) was distilled under reduced pressure after removal of the inhibitor by the usual method and kept cold before use. 4-Acetoxystyrene (A-St), $t$-Butyl 4-vinyl-phenyl carbonate (B-St), and 4-chlorostyrene $(\mathrm{C}-\mathrm{St})$ were used without further purification. Trimethyl(4-( $N$-maleimido)phenoxy) silane (TMMS) were prepared by the method of our previous paper. ${ }^{26}$ The synthesized products were dissolved in ethyl acetate and extracted by a $1 \% \mathrm{NaOH}$ solution. The organic layer was isolated and the remains, dried with anhydrous magnesium sulfate, were then dissolved in ethyl acetate and recrystallized several times with $n$-hexane. The silicon-containing maleimide monomers obtained were dried in vacuum. The characterization of this monomer synthesized was analyzed by the ${ }^{1} \mathrm{H},{ }^{13} \mathrm{C}$, ${ }^{29} \mathrm{Si}$ Nuclear Magnetic Resonance (NMR) spectroscopy, Fourier Transform Infrared (FT-IR) reflection spectroscopy and elemental analysis, respectively.

The initiator, AIBN, was recrystallized from ethanol and dried in a desiccator. Its melting point analyzed by DSC was found to be $104.1^{\circ} \mathrm{C}$. Tetrahydrofuran (THF) was distilled after dehydration with sodium. $N, N$-Dimethylformamide (DMF) was dried by $\mathrm{CaH}_{2}$ over night. The other solvents were purified by conventional methods.

\section{Synthesis of Copolymer}

A flask was charged with various ratios of styrene and maleimide monomers (MI) obtained as shown in Table I, AIBN as initiator $(5 \mathrm{mmol} / \mathrm{L})$ and toluene as solvent. The free radical copolymerization was carried out in a water bath thermostat at $70^{\circ} \mathrm{C}$ and the mixture was refluxed for a time in which the conversion of copolymerization was restricted to less than $10 \%$. The solvent was removed under reduced pressure, and then the polymerization mixture was again dissolved in dichloromethane and poured into a large
Table I. Properties of copolymers prepared from styrene monomers $\left(\mathrm{M}_{1}\right)$ and TMMS $\left(\mathrm{M}_{2}\right)$

\begin{tabular}{|c|c|c|c|c|c|c|}
\hline $\begin{array}{c}\text { Monomer } \\
\left(\mathrm{M}_{1}\right)\end{array}$ & $F_{1}{ }^{\mathrm{a}}$ & $\begin{array}{c}\text { Conversion } \\
(\%)\end{array}$ & $f_{1}{ }^{\mathrm{a}}$ & $\begin{array}{c}M_{\mathrm{w}}{ }^{\mathrm{b}} \\
\left(\times 10^{4}\right) \\
\end{array}$ & $\begin{array}{c}M_{\mathrm{n}}{ }^{\mathrm{b}} \\
\left(\times 10^{4}\right) \\
\end{array}$ & PDI \\
\hline \multirow[t]{7}{*}{ St } & 0.10 & 9.1 & 0.18 & 24.6 & 7.2 & 3.42 \\
\hline & 0.25 & 9.4 & 0.31 & 25.7 & 7.6 & 3.38 \\
\hline & 0.40 & 8.9 & 0.44 & 26.9 & 8.1 & 3.32 \\
\hline & 0.50 & 9.0 & 0.54 & 27.3 & 8.4 & 3.25 \\
\hline & 0.60 & 7.6 & 0.57 & 27.6 & 8.6 & 3.21 \\
\hline & 0.75 & 9.8 & 0.71 & 28.7 & 9.1 & 3.15 \\
\hline & 0.90 & 9.2 & 0.86 & 28.7 & 9.5 & 3.02 \\
\hline \multirow[t]{7}{*}{ A-St } & 0.10 & 9.0 & 0.14 & 20.4 & 5.8 & 3.51 \\
\hline & 0.25 & 8.8 & 0.28 & 21.7 & 6.3 & 3.45 \\
\hline & 0.40 & 9.6 & 0.42 & 23.2 & 6.8 & 3.41 \\
\hline & 0.50 & 9.3 & 0.52 & 23.6 & 7.0 & 3.37 \\
\hline & 0.60 & 9.4 & 0.64 & 24.6 & 7.4 & 3.32 \\
\hline & 0.75 & 9.9 & 0.74 & 25.6 & 7.8 & 3.28 \\
\hline & 0.90 & 9.2 & 0.88 & 26.4 & 8.2 & 3.22 \\
\hline \multirow[t]{7}{*}{ B-St } & 0.10 & 8.6 & 0.13 & 18.5 & 5.2 & 3.55 \\
\hline & 0.25 & 8.5 & 0.27 & 19.5 & 5.6 & 3.49 \\
\hline & 0.40 & 8.9 & 0.41 & 21.2 & 6.2 & 3.42 \\
\hline & 0.50 & 9.0 & 0.51 & 23.0 & 6.8 & 3.38 \\
\hline & 0.60 & 9.2 & 0.62 & 23.7 & 7.1 & 3.34 \\
\hline & 0.75 & 9.6 & 0.75 & 24.8 & 7.5 & 3.30 \\
\hline & 0.90 & 8.8 & 0.89 & 25.6 & 7.8 & 3.28 \\
\hline \multirow[t]{7}{*}{ C-St } & 0.10 & 8.7 & 0.17 & 24.2 & 7.0 & 3.45 \\
\hline & 0.25 & 8.7 & 0.29 & 25.2 & 7.4 & 3.41 \\
\hline & 0.40 & 9.2 & 0.43 & 26.6 & 7.9 & 3.37 \\
\hline & 0.50 & 9.2 & 0.53 & 26.8 & 8.1 & 3.31 \\
\hline & 0.60 & 9.0 & 0.56 & 27.2 & 8.4 & 3.24 \\
\hline & 0.75 & 9.7 & 0.73 & 27.7 & 8.8 & 3.15 \\
\hline & 0.90 & 9.5 & 0.87 & 28.0 & 9.1 & 3.08 \\
\hline
\end{tabular}

${ }^{\mathrm{a}} F_{1}$ and $f_{1}$ are the mole fraction of $\mathrm{M}_{1}$ in the feed and in the copolymers while $f_{1}$ are obtained from element analysis. ${ }^{b}$ Distribution of molecular weight are tested by GPC with a concentration of $0.5 \mathrm{wt} \%$ in THF.

amount of methanol. The copolymer then was isolated by filtration and dried under vacuum at $60^{\circ} \mathrm{C}$.

\section{Instrumentation}

The IR-spectra and elemental analyses $(\mathrm{C}, \mathrm{H}, \mathrm{N})$ of the St-MI copolymers were obtained by a Nicolet Omnic 3 Fourier Transform Infrared (FT-IR) reflection spectroscopy and a Heraeus CHN-O Rapid Analyzer, respectively. The molecular weight distributions of the St-MI copolymers were measured by a Waters Gel Permeation Chromatography (GPC, Waters 1515HPLC/2410RI-detector) at a flow rate of $1.0 \mathrm{~mL} / \mathrm{min}$ with a sample concentration of $0.5 \mathrm{wt} \%$ in THF as effluent flow. The system was first calibrated using standard samples of polystyrene with the narrow distribution of molecular weight. The thermal properties of the synthesized copolymers were investigated by DSC(TA-Instruments DSC - Q10) at a heating rate of $10^{\circ} \mathrm{C} / \mathrm{min}$ in $\mathrm{N}_{2}$, and TGA(TA-Instru- 


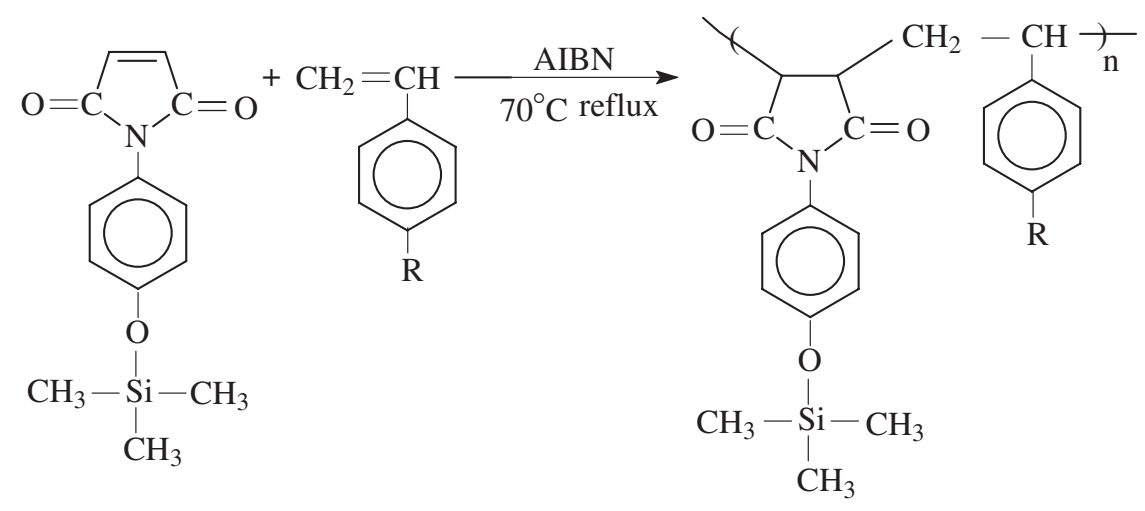<smiles>[R][13CH2]OC(C)=O</smiles>

Scheme 1. Synthesis of silicon-containing St-MI copolymer.

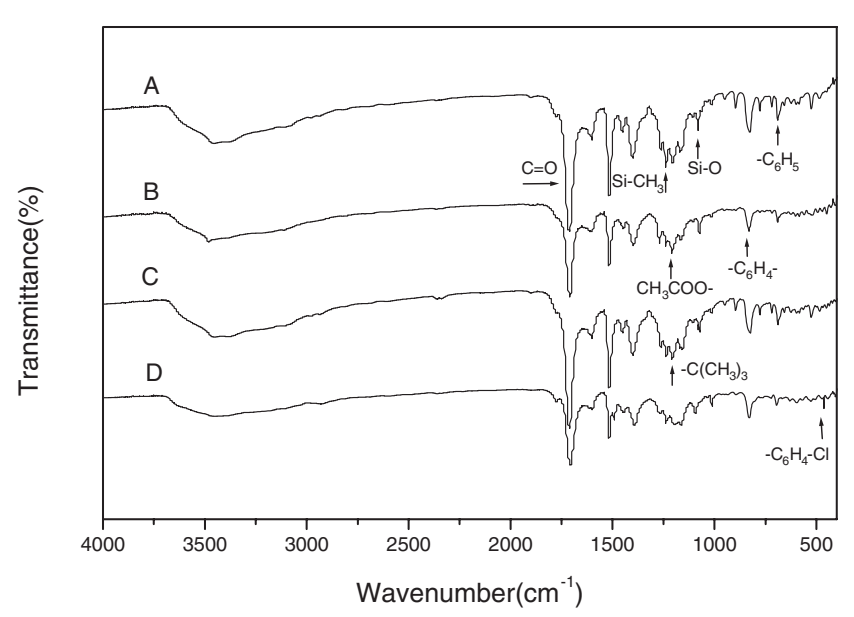

Figure 1. FT-IR spectra of A:St/MI(50\%), B:A-St/MI(50\%), $\mathrm{C}: \mathrm{B}-\mathrm{St} / \mathrm{MI}(50 \%)$ and D:C-St/MI(50\%) copolymer.

ments TGA -Q50) at a heating rate of $20^{\circ} \mathrm{C} / \mathrm{min}$ in air or $\mathrm{N}_{2}$, respectively.

\section{RESULTS AND DISCUSSION}

\section{Copolymerization and Copolymer Properties}

The copolymers of styrene-series with silicon-containing $N$-phenyl maleimide were synthesized by radical polymerization in toluene solution using AIBN as initiator as shown in Scheme 1.

The FT-IR spectra of St/MI(50\%), A-St/MI(50\%), $\mathrm{B}-\mathrm{St} / \mathrm{MI}(50 \%)$ and $\mathrm{C}-\mathrm{St} / \mathrm{MI}(50 \%)$ copolymers, as shown in Figure 1, revealed the absorption bands $v\left(\mathrm{~cm}^{-1}\right): 1240\left(\mathrm{Si}-\mathrm{CH}_{3}\right), 1080(-\mathrm{Si}-\mathrm{O})$ and $1706(\mathrm{C}=\mathrm{O})$ from TMMS; 700(mono-substitution of benzene) from styrene; 831(di-substitution of benzene) and 1210$\left(\mathrm{CH}_{3} \mathrm{COO}-\right)$ from A-St; $1270\left(-\mathrm{C}\left(\mathrm{CH}_{3}\right)_{3}\right)$ from B-St and $463\left(-\mathrm{C}_{6} \mathrm{H}_{4}-\mathrm{Cl}\right)$ from $\mathrm{C}-\mathrm{St}$ conforming that all the
4 series copolymers had been synthesized successfully.

Basic properties of St-MI copolymers in different silicon contents and molecular weights obtained from elemental analysis and GPC analysis are given in Table I. The average number molecular weights $\left(M_{\mathrm{n}}\right)$ of each copolymer series were approximately in the range $5.2-9.5 \times 10^{4}(\mathrm{~g} / \mathrm{mol})$. The $M_{\mathrm{n}}$ gradually decreased, while the polydispersity index (PDI $=$ $M_{\mathrm{w}} / M_{\mathrm{n}}$ ) increased along with the increasing maleimide monomers in feed. This might due to that the silicon-containing maleimide monomer could easily cause the chain transfer during copolymerization reaction. Besides, the copolymerization degree and average molecular weight might be affected by the sidechain effect and steric hinderance generated from maleimide and styrene segments. The sequence of intermolecular steric hinderance should be B-St $>$ A-St $>$ C-St $>$ St. Since B-St series copolymers would form a larger steric hinderance during copolymerization, a lower polymerization degree and a lower average molecular weight would be obtained.

Generally speaking, the double bond of $N$-phenyl maleimide as a result of the electron-withdrawing effect between carbonyl groups on both sides showed its reversed polarity versus styrene monomers. ${ }^{27}$ That means the unsaturated double bonds of $\mathrm{N}$-phenyl maleimide will be in a state of poor-electron and of styrene in a relatively rich-electron state. Then, there was a high tendency for them copolymerized to generate alternating-like St-MI copolymers with the reactivity ratios approaching to zero. The reactivity ratios of styrene/TMMS comonomers, as shown in Table II, were determined by the method of Fineman-Ross, ${ }^{28}$ Kelen-Tüdos, ${ }^{29}$ and Tidwell-Mortimer ${ }^{30}$ while all the instantaneous copolymer yield were under $10 \%$. All the reactivity ratio for the above copolymerization is 
Table II. Reactivity ratios of styrene monomers $\left(\mathrm{M}_{1}\right)$ and TMMS $\left(\mathrm{M}_{2}\right)$

\begin{tabular}{ccccccc}
\hline \multirow{2}{*}{$\begin{array}{c}\text { Monomer } \\
\left(\mathrm{M}_{1}\right)\end{array}$} & \multicolumn{2}{c}{ Fineman-Ross } & \multicolumn{2}{c}{ Kelen-Tüdos } & \multicolumn{2}{c}{ Tidwell-Mortimer } \\
\cline { 2 - 6 }${ }_{1}$ & $r_{2}$ & $r_{1}$ & $r_{2}$ & $r_{1}$ & $r_{2}$ \\
\hline $\mathrm{St}$ & $0.61 \pm 0.04$ & $0.52 \pm 0.15$ & 0.59 & 0.48 & 0.60 & 0.49 \\
$\mathrm{~A}-\mathrm{St}$ & $0.83 \pm 0.02$ & $0.68 \pm 0.10$ & 0.82 & 0.67 & 0.81 & 0.66 \\
$\mathrm{~B}-\mathrm{St}$ & $0.89 \pm 0.02$ & $0.78 \pm 0.10$ & 0.88 & 0.77 & 0.86 & 0.76 \\
$\mathrm{C}-\mathrm{St}$ & $0.66 \pm 0.03$ & $0.57 \pm 0.15$ & 0.65 & 0.55 & 0.64 & 0.54 \\
\hline
\end{tabular}

no longer nearby zero but changed to $0.48-0.88$, and is larger than that of the general St-MI copolymerization. ${ }^{10-13}$ This was mainly due to the electron-withdrawing effect of silane side chains to inhibit the carbonyl pairs withdrawing electron effect of double bond within maleimide. Besides, the polarity of styrenes was also affected by their deactivators. The result of the reducing reversed polarity of double bond of TMMS relative to that of styrenes indicated that the above comonomers reaction had changed from a alternating to middle type between alternating and ideal copolymerization. As shown in Table I, all the 4 copolymerization systems, furthermore, exhibit azeotropic points (for example the system of B-St at about $\left.F_{1}=f_{1}=0.75\right)$ that represent a composition where polymerization proceeds to relatively high conversion with no change in either feed ratio or copolymer composition.

As shown in Table II, the reactivity orders of TMMS-terminated radical towards the 4 series of styrene monomers was $\mathrm{St}>\mathrm{C}$-St $>\mathrm{A}$-St $>\mathrm{B}$-St, indicating that these copolymerizations were also affected by the properties of different side chains within styrene monomers. Since the deactivity effect of ester groups were higher than chlorine or hydrogen atoms, all the molecular weight, PDI or comonomer's reactivity ratio should, therefore, be affected by both steric hinderance and polarity factors of TMMS side chains and the deactivators of styrene simultaneously.

\section{Thermal Properties of Copolymers}

Glass Transition Temperature. Glass transition temperature $\left(T_{\mathrm{g}}\right)$ of copolymers is one of the important physical properties that may be affected by their composition and morphology. All the $T_{\mathrm{g}}$ data of the 4 series of copolymers are given in Table III. Since the molecular weights of all the 4 series of copolymers were higher than $5.2 \times 10^{4}$ (see Table I), the effect of molecular weight on $T_{\mathrm{g}}$ was not significant. The DSC measurement for all the copolymers showed that all St-MI copolymers had a single $T_{\mathrm{g}}$ that would increase along with the increasing maleimide content. This means that maleimide-segments and styrene-segments within the copolymers should be completely compatible. Theoretically, $T_{\mathrm{g}}$ of the copolymers should comply with the Fox equation: ${ }^{31}$
Table III. Glass transition temperatures of copolymers prepared from styrene monomers $\left(\mathrm{M}_{1}\right)$ and TMMS $\left(\mathrm{M}_{2}\right)$

\begin{tabular}{|c|c|c|c|c|c|}
\hline Copolymer & $f_{2}{ }^{\mathrm{a}}$ & $W_{2}^{\mathrm{b}}$ & $T_{\mathrm{g}}\left({ }^{\circ} \mathrm{C}\right)^{\mathrm{c}}$ & $T_{\mathrm{g}}(\mathrm{K})$ & $T_{\mathrm{g} 12}(\mathrm{~K})^{\mathrm{d}}$ \\
\hline \multirow[t]{9}{*}{$\mathrm{MI} / \mathrm{St}$} & 0.00 & 0.00 & 98 & 371 & 366 \\
\hline & 0.14 & 0.29 & 126 & 399 & \\
\hline & 0.27 & 0.48 & 139 & 412 & \\
\hline & 0.43 & 0.65 & 142 & 415 & \\
\hline & 0.46 & 0.68 & 144 & 417 & \\
\hline & 0.56 & 0.76 & 147 & 420 & \\
\hline & 0.69 & 0.85 & 153 & 426 & \\
\hline & 0.82 & 0.92 & 161 & 434 & \\
\hline & 1.00 & 1.00 & 172 & $445^{\mathrm{e}}$ & \\
\hline \multirow[t]{8}{*}{$\mathrm{MI} / \mathrm{A}-\mathrm{St}$} & 0.00 & 0.00 & 144 & 417 & 390 \\
\hline & 0.12 & 0.18 & 151 & 424 & \\
\hline & 0.26 & 0.36 & 155 & 428 & \\
\hline & 0.36 & 0.48 & 157 & 430 & \\
\hline & 0.48 & 0.60 & 159 & 432 & \\
\hline & 0.58 & 0.69 & 161 & 434 & \\
\hline & 0.72 & 0.81 & 164 & 437 & \\
\hline & 0.86 & 0.91 & 167 & 440 & \\
\hline \multirow[t]{8}{*}{ MI/B-St } & 0.00 & 0.00 & 156 & 429 & 404 \\
\hline & 0.11 & 0.14 & 160 & 433 & \\
\hline & 0.25 & 0.30 & 161 & 434 & \\
\hline & 0.38 & 0.44 & 162 & 435 & \\
\hline & 0.49 & 0.55 & 163 & 436 & \\
\hline & 0.59 & 0.65 & 165 & 438 & \\
\hline & 0.73 & 0.78 & 167 & 440 & \\
\hline & 0.87 & 0.89 & 169 & 442 & \\
\hline \multirow[t]{8}{*}{$\mathrm{MI} / \mathrm{C}-\mathrm{St}$} & 0.00 & 0.00 & 106 & 379 & 368 \\
\hline & 0.13 & 0.22 & 124 & 397 & \\
\hline & 0.27 & 0.41 & 137 & 410 & \\
\hline & 0.44 & 0.59 & 141 & 414 & \\
\hline & 0.47 & 0.63 & 143 & 416 & \\
\hline & 0.57 & 0.71 & 147 & 420 & \\
\hline & 0.71 & 0.82 & 153 & 426 & \\
\hline & 0.83 & 0.92 & 161 & 434 & \\
\hline
\end{tabular}

${ }^{\text {a }}$ Mole fraction of $\mathrm{M}_{2}$ within the copolymer. ${ }^{\mathrm{b}}$ Weight fraction of $\mathrm{M}_{2}$ within the copolymer. ${ }^{\mathrm{c}}$ The glass transition temperature $\left(T_{\mathrm{g}}\right)$ is analyzed by DSC at a heating rate of $10^{\circ} \mathrm{C} / \mathrm{min}$ in $\mathrm{N}_{2}$. ${ }^{\mathrm{d}}$ Glass transition temperature calculated by the modified

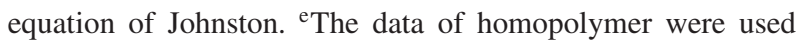
from the previous study (ref 26).

$$
\frac{1}{T_{\mathrm{g}}}=\frac{W_{1}}{T_{\mathrm{g} 1}}+\frac{W_{2}}{T_{\mathrm{g} 2}}
$$

where $W_{\mathrm{i}}$ was the weight fraction of comonomer $\mathrm{i}$ within the copolymer and $T_{\mathrm{gi}}$ was the homopolymer's 


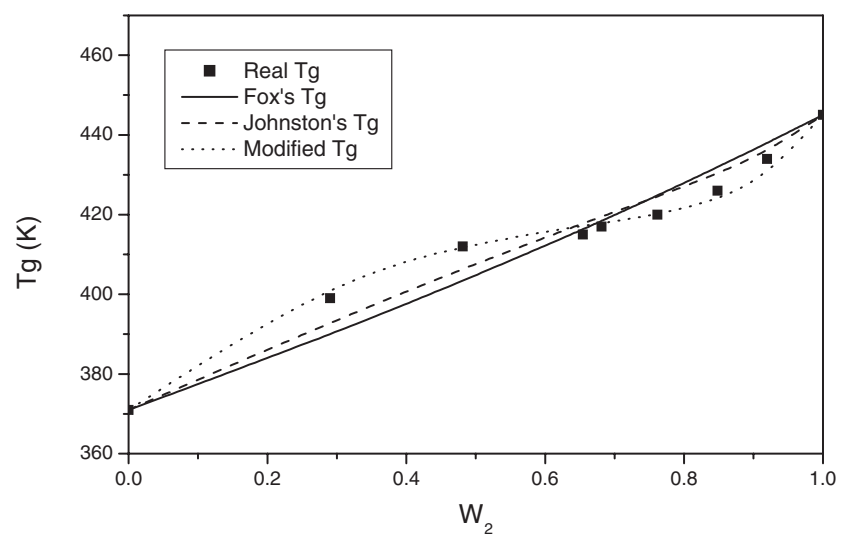

Figure 2. Variation of $T_{\mathrm{g}}$ as a function of the weight fraction of TMMS $\left(W_{2}\right)$ for the St-MI copolymer system.

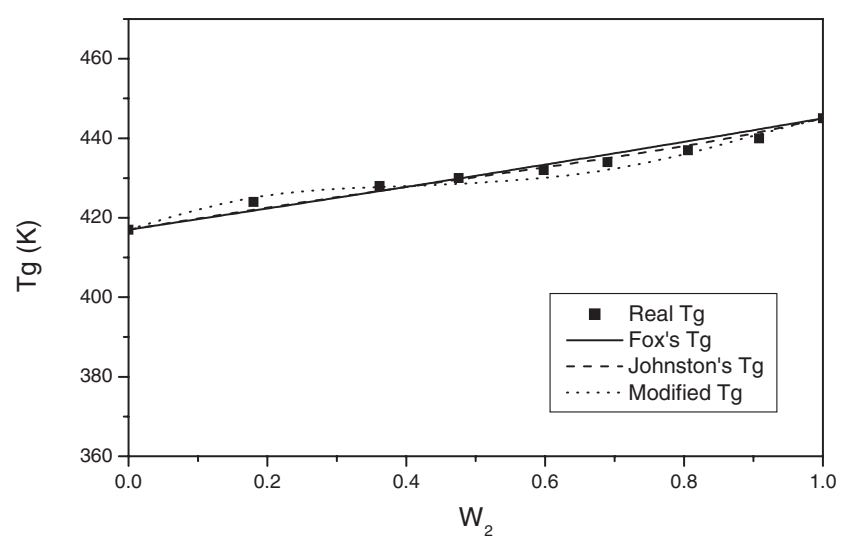

Figure 3. Variation of $T_{\mathrm{g}}$ as a function of the weight fraction of TMMS $\left(W_{2}\right)$ for the A-St/MI copolymer system.

$T_{\mathrm{g}}$ of comonomer i.

By substituting $T_{\mathrm{gi}}$ into eq 1 , the real $T_{\mathrm{g}}$ s of copolymers matching the Fox theory could be obtained. The relationships between the Fox's $T_{\mathrm{g}}$-curve and actual $T_{\mathrm{g}}$ 's values, measured by DSC, versus the copolymer compositions are shown in Figures 2-5. Considering the segment structure of TMMS, although its silicon-containing side chain was high mobile segment, molecular motions of these segments could only proceed under a relatively higher temperature or energy due to the high rigidity of the imide structure. As shown in Table III, the $T_{\mathrm{g}} \mathrm{s}$ of TMMS homopolymer and all the copolymers were higher than that of polystyrene series, indicating that the rigid degree of the former was higher than that of the latter. In Figures $2-5$, the actual $T_{\mathrm{g}}$ curves of copolymers in comparison with the Fox's curves exhibited the positive/negative deviations. The S-like curve of $T_{\mathrm{g}}$ in blending polymer system had also been studied in literature. ${ }^{32}$ The $T_{\mathrm{g}}$ of the alternating segments within copolymer $\left(T_{\mathrm{g} 12}\right)$ should affect the $T_{\mathrm{g}}$ of the overall copolymer significantly. Besides, each of the 4 series copolymers had a $T_{\mathrm{g}}$ value conformed to match the Fox theory (the

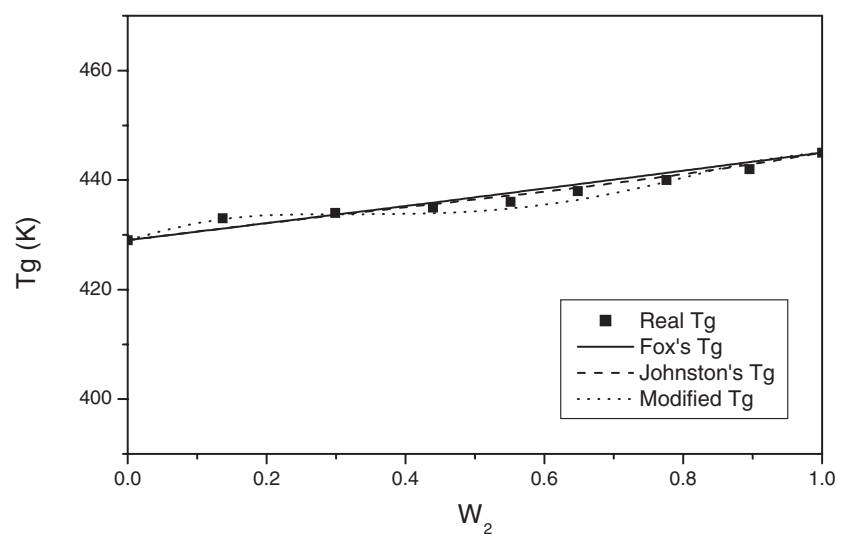

Figure 4. Variation of $T_{\mathrm{g}}$ as a function of the weight fraction of TMMS $\left(W_{2}\right)$ for the B-St/MI copolymer system.

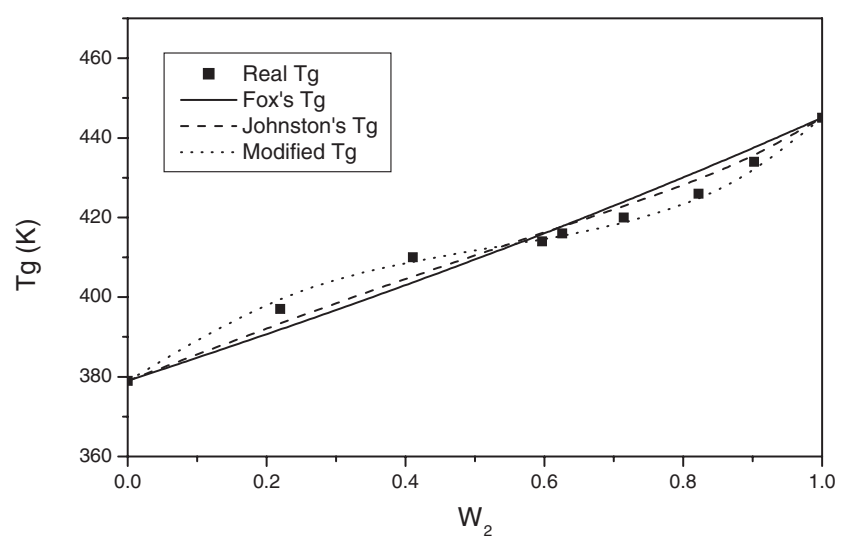

Figure 5. Variation of $T_{\mathrm{g}}$ as a function of the weight fraction of TMMS $\left(W_{2}\right)$ for the C-St/MI copolymer system.

value at the intersection with Fox's curve), postulating that the comonomer segment-distribution for copolymer in azeotropic composition was more random than that in the others leading to offset the alternate segment effect. On the other hand, except the copolymer with azeotropic composition, the molecular motion of the others was easily affected by its alternate segment. Therefore, a higher content of silicon-containing maleimide segment within copolymer would produce a negative deviation of $T_{\mathrm{g}}$ due to the effect of styrene segment, and on the contrary, a lower content would produce a positive deviation of $T_{\mathrm{g}}$ due to the effect of maleimide segment. In order to understand the effect of the alternate segment for the actual $T_{\mathrm{g}} \mathrm{s}$ of copolymers, the Johnston's equation ${ }^{33}$ modified from Fox theory was applied:

$$
\frac{1}{T_{\mathrm{g}}}=\frac{W_{1} P_{11}}{T_{\mathrm{g} 11}}+\frac{W_{2} P_{22}}{T_{\mathrm{g} 22}}+\frac{W_{1} P_{12}+W_{2} P_{21}}{T_{\mathrm{g} 12}}
$$

where $P_{\mathrm{ij}}$ : probability of forming ij-segment, $T_{\mathrm{gii}}$ : homopolymer's $T_{\mathrm{g}}$ of comonomer $\mathrm{i}$, and $T_{\mathrm{gij}}$ : glass transition temperature of alternating segment within copolymer. The $P_{\mathrm{ij}}$ could be calculated as: 


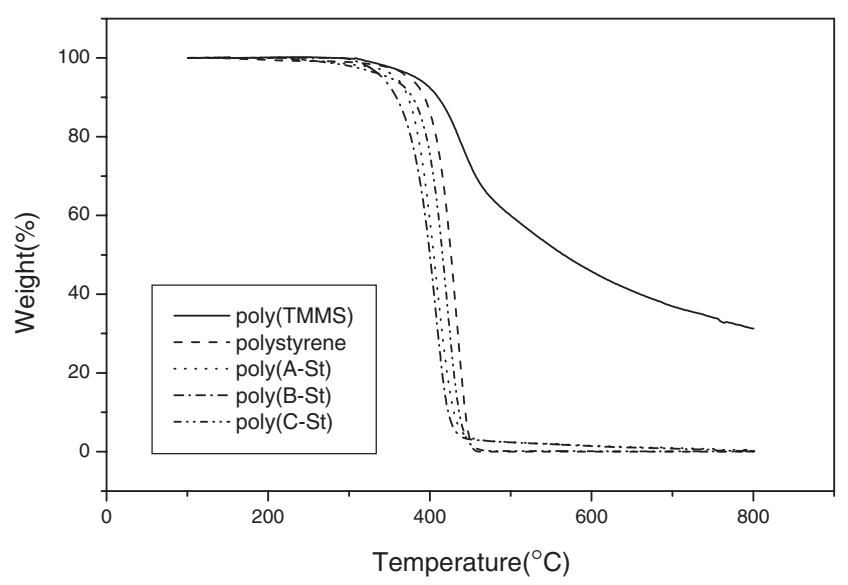

Figure 6. TGA traces of poly(TMMS) and polystyrene series homopolymers in $\mathrm{N}_{2}$.

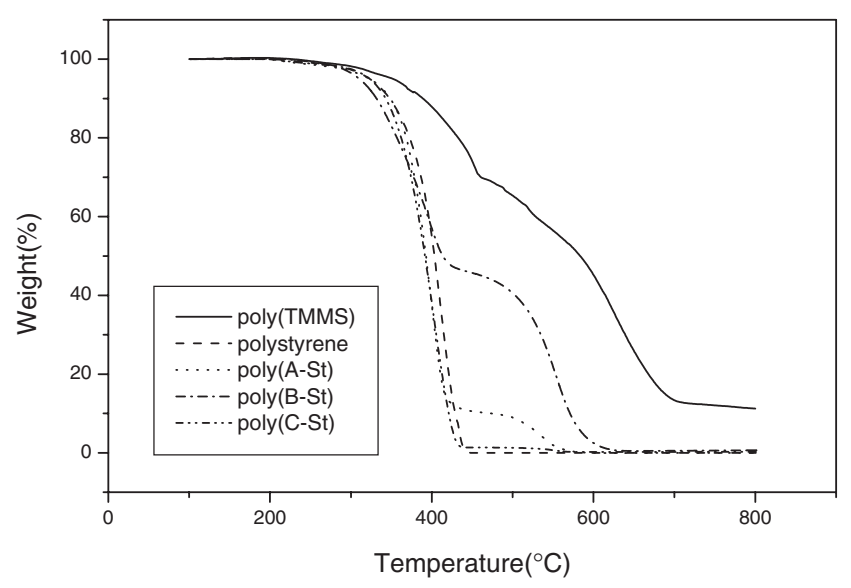

Figure 7. TGA traces of poly(TMMS) and polystyrene series homopolymers in air.

$$
\begin{aligned}
& P_{12}=\frac{1}{1+r_{1} \frac{[1]}{[2]}}=\frac{1}{1+r_{1} \frac{f_{1}}{f_{2}}} \\
& P_{11}=1-P_{12} \\
& P_{21}=\frac{1}{1+r_{2} \frac{[2]}{[1]}}=\frac{1}{1+r_{2} \frac{f_{2}}{f_{1}}} \\
& P_{22}=1-P_{21}
\end{aligned}
$$

It could also be noticed in Figures 2-5 that the Johnston's curves of copolymers did not match the actual $T_{\mathrm{g}}$ curves. That means the effect of its $T_{\mathrm{g} 12}$ on the real $T_{\mathrm{g}}$ of copolymer cannot be sufficiently described by Johnston's equation. Considering the influence of $T_{\mathrm{g} 12}$ that should be more significant, a modified Johnston's equation can be taken as following: ${ }^{34}$

$$
\frac{1}{T_{\mathrm{g}}}=\frac{W_{1} P_{11}}{T_{\mathrm{g} 11}}+\frac{W_{2} P_{22}}{T_{\mathrm{g} 22}}+\frac{W_{1}{ }^{\alpha} P_{12}+W_{2}{ }^{\alpha} P_{21}}{T_{\mathrm{g} 12}}
$$

where $\alpha$ is a parameter according to the effect of alter-

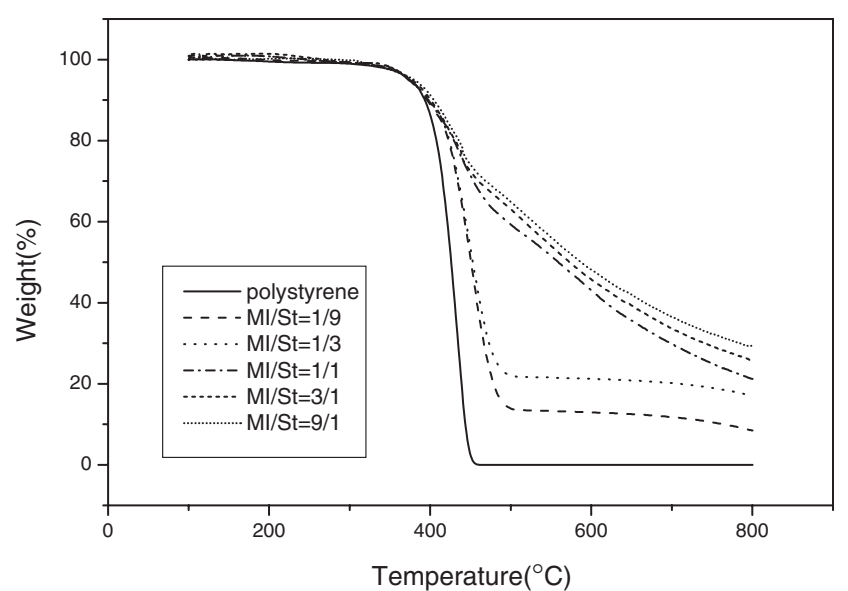

Figure 8. TGA traces of Styrene-TMMS copolymers in $\mathrm{N}_{2}$.

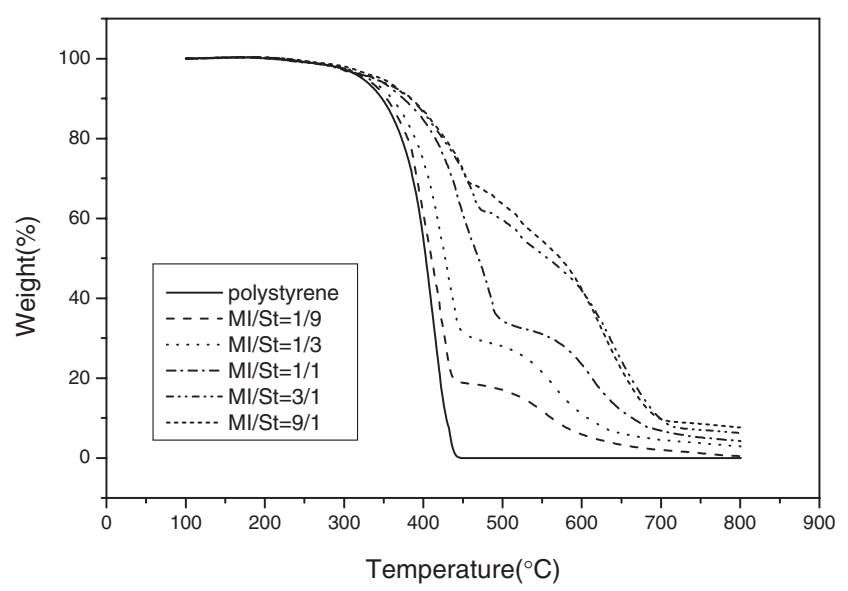

Figure 9. TGA traces of Styrene-TMMS copolymers in air.

nating segment. Substitution of actual $T_{\mathrm{g}}$ of all the 4 series copolymers into the eq 3 gave an average of $T_{\mathrm{g} 12}$ so as to obtain the modified $T_{\mathrm{g}}-W_{2}$ curves. The value $\alpha$ was determined by a try-and-error method so as to make the modified $T_{\mathrm{g}}-W_{2}$ curves approaching to the actual $T_{\mathrm{g}}$ as possible as it can be. It could also be noticed from Figures $2-5$ that the actual $T_{\mathrm{g}}$ of all the 4 series of copolymers were proved to match our modified curves while $\alpha=1.24$ in St, $\alpha=1.14$ in A-St, $\alpha=1.10$ in B-St, and $\alpha=1.22$ in C-St series. That means the $T_{\mathrm{g}}$ of these copolymers could be sufficiently described by our modified equation as a result of increasing the affect of weight ratio on $T_{\mathrm{g} 12}$. Besides, the S-shaped curve of deviation is more not obvious as the difference of $T_{\mathrm{g}}$ between comonomers is small like B-St system.

\section{Thermal Stability}

Thermal properties of 4 series St-MI copolymers and homopolymers measured by TGA in $\mathrm{N}_{2}$ or air as shown in Figures 6-9 are also listed in Table IV. As seen in Figure 6 and Table IV, $T_{5 \%}$ of all the sty- 
Poly(Styrene-co-Silicon-containing maleimide)

Table IV. Thermal properties of copolymers prepared from styrene monomers $\left(\mathrm{M}_{1}\right)$ and TMMS $\left(\mathrm{M}_{2}\right)$

\begin{tabular}{|c|c|c|c|c|c|c|c|}
\hline \multirow{2}{*}{$\begin{array}{l}\text { Monomer } \\
\left(\mathrm{M}_{1}\right)\end{array}$} & \multirow{2}{*}{$F_{1}{ }^{\mathrm{a}}$} & \multirow{2}{*}{$f_{1}{ }^{\mathrm{b}}$} & \multirow{2}{*}{$\mathrm{Si}(\%)^{\mathrm{c}}$} & \multicolumn{2}{|c|}{5 wt $\% \operatorname{Loss}\left({ }^{\circ} \mathrm{C}\right)^{\mathrm{d}}$} & \multicolumn{2}{|c|}{ Char at $800^{\circ} \mathrm{C}(\%)^{\mathrm{d}}$} \\
\hline & & & & $\mathrm{N}_{2}$ & Air & $\mathrm{N}_{2}$ & Air \\
\hline \multirow[t]{7}{*}{ St } & 1.00 & 1.00 & 0.0 & 373 & 323 & 0.0 & 0.0 \\
\hline & 0.90 & 0.86 & 3.1 & 374 & 327 & 8.4 & 0.5 \\
\hline & 0.75 & 0.73 & 5.2 & 375 & 332 & 17.2 & 2.9 \\
\hline & 0.50 & 0.54 & 7.3 & 376 & 338 & 21.1 & 4.2 \\
\hline & 0.25 & 0.31 & 9.0 & 378 & 342 & 25.8 & 6.2 \\
\hline & 0.10 & 0.18 & 9.9 & 380 & 348 & 29.3 & 7.7 \\
\hline & 0.00 & 0.00 & 10.7 & 384 & 352 & 31.3 & 12.0 \\
\hline \multirow[t]{7}{*}{ A-St } & 1.00 & 1.00 & 0.0 & 345 & 323 & 0.2 & 0.0 \\
\hline & 0.90 & 0.88 & 1.9 & 348 & 326 & 8.5 & 0.8 \\
\hline & 0.75 & 0.74 & 3.9 & 355 & 330 & 18.1 & 2.6 \\
\hline & 0.50 & 0.52 & 6.4 & 363 & 338 & 22.4 & 4.5 \\
\hline & 0.25 & 0.28 & 8.6 & 374 & 344 & 26.5 & 6.8 \\
\hline & 0.10 & 0.14 & 9.7 & 381 & 349 & 29.2 & 8.1 \\
\hline & 0.00 & 0.00 & 10.7 & 384 & 352 & 31.3 & 12.0 \\
\hline \multirow[t]{7}{*}{ B-St } & 1.00 & 1.00 & 0.0 & 341 & 320 & 0.4 & 0.2 \\
\hline & 0.90 & 0.89 & 1.5 & 344 & 322 & 6.2 & 0.4 \\
\hline & 0.75 & 0.75 & 3.2 & 351 & 327 & 15.8 & 2.3 \\
\hline & 0.50 & 0.51 & 5.9 & 361 & 335 & 21.7 & 4.0 \\
\hline & 0.25 & 0.27 & 8.3 & 372 & 343 & 23.6 & 6.2 \\
\hline & 0.10 & 0.13 & 9.6 & 379 & 348 & 26.1 & 7.8 \\
\hline & 0.00 & 0.00 & 10.7 & 384 & 352 & 31.3 & 12.0 \\
\hline \multirow[t]{7}{*}{ C-St } & 1.00 & 1.00 & 0.0 & 350 & 323 & 0.0 & 0.3 \\
\hline & 0.90 & 0.87 & 2.4 & 354 & 326 & 8.1 & 0.5 \\
\hline & 0.75 & 0.73 & 4.4 & 359 & 331 & 17.0 & 2.2 \\
\hline & 0.50 & 0.53 & 6.7 & 368 & 339 & 20.9 & 4.1 \\
\hline & 0.25 & 0.29 & 8.8 & 378 & 346 & 25.5 & 6.0 \\
\hline & 0.10 & 0.17 & 9.7 & 381 & 350 & 29.0 & 7.1 \\
\hline & 0.00 & 0.00 & 10.7 & 384 & 352 & 31.3 & 12.0 \\
\hline
\end{tabular}

${ }^{a}$ Mole fraction of $\mathrm{M}_{1}$ in the feed. ${ }^{\mathrm{b}}$ Mole fraction of $\mathrm{M}_{1}$ within the copolymer. ${ }^{\mathrm{c}}$ The theoretical calculation values of Si composition ratio. ${ }^{\mathrm{d}}$ Thermal properties are analyzed by TGA at a heating rate of $20{ }^{\circ} \mathrm{C} / \mathrm{min}$ in $\mathrm{N}_{2}$ or in air. ${ }^{\mathrm{e}}$ Homopolymer of St, A-St, B-St and C-St with a $M_{\mathrm{n}}$ about $1.5 \times 10^{5}, 5 \times 10^{4}, 4.5 \times 10^{4}$ and $7.5 \times 10^{4}$.

rene series homopolymers was higher than $341^{\circ} \mathrm{C}$ when were heated under nitrogen gas. The A-St and B-St homopolymers exhibited a lower $T_{5 \%}$ due to the decomposition reactions of their ester side-chains. Decomposition reactions of TMMS homopolymer should be initialized mainly by scission of silane side-chains because of owning lower bond energy, ${ }^{26}$ and further produced scission of the maleimide mainchain along with carbonization to form char yield of solid residue. Thermal stability of all the homopolymers in $\mathrm{N}_{2}$ was higher than that in air because of the oxidization reaction. When all homopolymers were heated in air, as shown in Figure 7, decomposition of TMMS, A-St and B-St series changed from one-stage to two-stage. The decomposition of the second stage should be the oxidized combustion reaction of ester, silane or imide fragment under the high temperature.

The TGA traces of St-MI copolymers measured in nitrogen and air are shown in Figures 8 and 9, respectively. The scission of all the copolymers in nitrogen and air was a 1-stage and a 2-stage process, respectively. Decomposition reactions in $\mathrm{N}_{2}$, as shown in Figure 8 , should be initialized mainly by scission of silane side-chains, and further produced scission of the maleimide and styrene main-chain along with carbonization to form char yield of solid residue. Thermal stability of all the St-MI copolymers in $\mathrm{N}_{2}$ was higher than that in air because of the oxidization reaction. When all copolymers were heated in air, decomposition, as shown in Figure 9, changed from onestage to two-stage. The decomposition of the second stage should be the oxidized combustion reaction under the high temperature. The char yield of the siliconcontaining copolymer pyrolyzed in air was generally increased with increasing the silicon content. This might due to the high oxidation resistance of silicon-containing solid residue, such as silicon oxide or silicon-carbon alloy. ${ }^{35}$ Besides, maximum rates of weight loss of these polymers were decreased and the pyrolysis curves moved to higher temperature as the silicon content was increased. The results of high- 
er char yield and lower weight loss rates during pyrolysis of silicon-containing system showed that the introduction of silane side-chain into polymers improved flame retardancy.

The TGA traces of 4 styrene series copolymers measured in nitrogen and air are alike. As comparing to the $T_{5 \%}$ in Table IV, the thermal stability of each copolymer series was higher than that of styrene-series homopolymers. The initial temperature of pyrolysis of all the 4 series copolymer was generally increased with increasing the TMMS content. This means that the silicon-containing side chains could increase thermal stability of copolymers in nitrogen or in air. Also, the char yield of all the 4 series copolymer was generally increased with increasing the silicon content both in $\mathrm{N}_{2}$ and in air environment. The higher char yield and lower weight loss rates showed that the introduction of silane side-chain into polymers improved flame retardancy.

\section{CONCLUSION}

The radical copolymerizations of 4 styrene-series with silicon-containing maleimide were carried out to get some novel copolymers. The factors, such as steric hinderance and chain transfer caused by silicon-containing maleimide, could affect the molecular weight, polydispersity index and segments distribution of copolymer. The actual $T_{\mathrm{g}} \mathrm{s}$ ' curves versus the composition ratios for all the above copolymers were very consistent with the modified Johnston's equation as increasing the weight ratio of alternate segments. The maleimide-segments and styrene-segments within these copolymers were completely compatible and the thermal stability and flame retardancy of polystyrene could be enhanced simultaneously via the introduction of silicon-containing maleimide.

Acknowledgment. The author would like to acknowledge the financial support for this research of the National Science Council, Taiwan, under the contact NSC 94-2622-E-233-001.

\section{REFERENCES}

1. D. C. Wu, C. Y. Hong, C. Y. Pan, and W. D. He, Polym. Int., 52, 98 (2003).

2. F. Yilmaz, L. Cianga, Y. Guner, L. Topppare, and Y. Yagci, Polymer, 45, 5765 (2004).

3. C. Soykan and I. Erol, J. Appl. Polym. Sci., 91, 964 (2004).

4. G. Liu, L. Zhang, C. Gao, and X. Qu, J. Appl. Polym. Sci., 98, 1932 (2005).

5. S. L. Oswal, N. S. Sarkar, V. K. Bhandari, H. B. Oza, and C. B. Patel, Iranian Polym. J., 13, 297 (2004).

6. C. B. Patel, N. I. Malek, and S. L. Oswal, J. Macromol. Sci.,
Part A: Pure Appl. Chem., 43, 289 (2006).

7. T. Cakir, I. E. Serhatli, and A. Onen, J. Appl. Polym. Sci., 99, 1993 (2006).

8. W. Y. Chiang and F. C. Ding, J. Polym. Res., 7, 251 (2000).

9. I. A. Salman, Al-Sagheer, A. Fakhria, and M. Z. Elsabee, J. Macromol. Sci., Part A: Pure Appl. Chem., 34, 1207 (1997).

10. J. A. Seiner and M. Litt, Macromolecules, 4, 308 (1971).

11. R. E. Cais, R. G. Farmer, D. J. T. Hill, and J. H. O'Donnell, Macromolecules, 12, 835 (1979).

12. M. Wang, X. Zhu, and L. Zhang, J. Appl. Polym. Sci., 75, 267 (2000).

13. M. Switala-Zeliazkow, Polym. Degrad. Stab., 74, 579 (2001).

14. W. Y. Chiang and J. Y. Lu, J. Appl. Polym. Sci., 50, 1007 (1993).

15. K. D. Ahn, J. S. Koo, and C. M. Chung, J. Polym. Sci., Part A: Polym. Chem., 34, 183 (1996).

16. T. Iijima, M. Hirano, W. Fukuda, and M. Tomoi, Eur. Polym. J., 29, 1399 (1993).

17. M. N. Teerenstra, D. R. Suwier, B. Van Mele, L. Teuwen, M. Maassen, H. J. Van Den Berg, and C. E. Koning, J. Polym. Sci., Part A: Polym. Chem., 38, 3550 (2000).

18. D. R. Suwier, P. A. M. Steeman, M. N. Teerenstra, M. A. J. Schellekens, B. Vanhaecht, M. J. Monteiro, and C. E. Koning, Macromolecules, 35, 6210 (2002).

19. S. T. Kim, J. B. Kim, C. M. Chung, and K. D. Ahn, J. Appl. Polym. Sci., 66, 2507 (1997).

20. K. D. Ahn, D. I. Koo, and C. G. Willson, Polymer, 36, 2621 (1995).

21. K. D. Ahn, C. M. Chung, H. S. Jo, and J. M. Rhee, Polym. Int., 47, 407 (1998).

22. W. Y. Chiang and Y. C. Lin, J. Appl. Polym. Sci., 83, 2791 (2002).

23. W. Y. Chiang and M. L. Lee, J. Appl. Polym. Sci., 90, 1032 (2003).

24. G. N. Taylor, T. M. Wolf, and L. E. Stillwagon, Solid State Technol., 27, 145 (1984).

25. C. X. Chen, R. J. Hurditch, D. W. Johnson, and D. J. Nawrocki, Proceedings of SPIE, The International Society for Optical Engineering, 4690 I, 262 (2002).

26. W. J. Shu, J. C. Ho, and L. H. Perng, Eur. Polym. J., 41, 149 (2005).

27. S. R. Turner, R. A. Arcus, C. G. Houle, and W. R. Schleigh, Polym. Eng. Sci., 26, 1096 (1986).

28. M. Fineman and S. D. Ross, J. Polym. Sci., 2, 259 (1950).

29. T. Kelen and F. Tüdos, J. Macromol. Sci. Pt. A, Chem., 9, 1 (1975).

30. P. W. Tidwell and G. A. Mortimer, J. Polym. Sci., Part A, 3, 369 (1965).

31. T. G. Fox, Bull. Am. Phys. Soc., 1, 123 (1956).

32. T. K. Kwei, J. Polym. Sci., Polym. Lett. Ed., 22, 307 (1984).

33. N. W. Johnston, J. Macromol. Sci., Rev. Macromol. Chem., C14, 215 (1976).

34. W. J. Shu, L. H. Perng, W. K. Chin, and C. Y. Hsu, J. Macromol. Sci., Part A: Pure Appl. Chem., 40, 897 (2003).

35. M. Foster, B. Darlington, J. Scharff, and A. Campion, Surf. Sci., 375, 35 (1997). 